\title{
INCLUSÕES FLUIDAS EM GEMAS BRASILEIRAS
}

\author{
R.M.da S.Bello ${ }^{1}$ \\ D.P.Svisero ${ }^{1}$ \\ A.L.Gandini ${ }^{2}$ \\ J.C.Mendes ${ }^{2}$ \\ J.V.Valarelli ${ }^{1}$ \\ R.A.Schultz-Güttler ${ }^{1}$
}

O Brasil é um dos maiores produtores de gemas coradas da atualidade. São encontradas no território brasileiro, especialmente no estado de Minas Gerais, algumas das mais importantes jazidas de esmeralda, água marinha, topázio imperial, turmalina, crisoberilo, hiddenita, kunzita, alexandrita, morganita, heliodoro, além de uma série de gemas de ocorrência mais rara tais como fenacita, euclásio, andalusita, diopsídio, escapolita, brasilianita, etc. A maior parte dessas jazidas é ainda pouco conhecida do ponto de vista geológico e genético. $O$ projeto, ora em andamento, tem por objetivo caracterizar a mineralogia e estudar as inclusões fluidas de alguns depósitos de minerais-gema procurando reunir elementos para a melhor compreensão dos processos genéticos. Até o presente momento, foram estudados com maior detalhe o topázio imperial da região de Ouro Preto (MG) e a esmeralda do Garimpo de Capoeirana, Nova Era (MG). Encontram-se ainda em fase de estudos as ocorrências de ametista de Caçapava (RS), a andalusita de Santa Tereza (ES), a turmalina de São José da Safira (MG), a ametista de Carajás (PA) e a água marinha de Coronel Murta (MG).

Esmeraldas de Capoeirana. As esmeraldas do garimpo de Capoeirana, localizado a 8,5 km a noroeste do município de Nova Era (MG) descoberto em 1988 (SOUZA et al., 1989, EPSTEIN, 1989) ocorrem predominantemente sob a forma de fragmentos de 1 a 3

\footnotetext{
Departamento de Mineralogia e Petrologia, Instituto de Geociências/USP, São Paulo.

2 Universidade Federal de Ouro Preto/Pós-graduação; Instituto de Geociências/USP, São Paulo.
} 
$\mathrm{cm}$, de hábito quase sempre subidiomórfico, constituído pelo prisma hexagonal com o pinacóide basal. Aparecem como monocristais isolados, ou em grupos de poucos cristais constituindo agregados de formas irregulares. Observadas ao microscópio, revelaram grande quantidade de inclusões fluidas, principalmente sob a forma de canalículos, de várias dimensões, orientados segundo seu eixo c; também ocorrem algumas inclusões equidimensionais sob a forma de cristais negativos (SOUZA et al., 1990).

O estudo microtermométrico dessas inclusōes mostrou serem elas compostas essencialmente por $\mathrm{H}_{2} \mathrm{O}$ e $\mathrm{CO}_{2}$ (volume de $\mathrm{CO}_{2} /$ volume total=0,70), estando presentes, em certos casos, um ou mais sólidos. Os resultados obtidos foram: temperaturas de fusão do $\mathrm{CO}_{2}$ $\left(\mathrm{TfCO}_{2}\right)$ entre $-56,9$ e $-56,7^{\circ} \mathrm{C}$, mostrando apenas uma ligeira depressão em relação à $\mathrm{TfCO}_{2}$ puro $\left(-56,6^{\circ} \mathrm{C}\right)$. Em algumas amostras encontraram-se $\mathrm{TfCO}_{2}$ mais baixas, sugerindo variações nas composiçōes dos fluidos mineralizantes em certos locais. As temperaturas de homogeneização do $\mathrm{CO}_{2}\left(\mathrm{ThCO}_{2}\right)$ apresentaram maior freqüência de variação entre 29,0 e $30,5^{\circ} \mathrm{C}$, fornecendo densidade média de $\mathrm{CO}_{2}$ de $0,61 \mathrm{~g} / \mathrm{cm}^{3}$. As temperaturas de fusão de clatratos (Tfclatratos) situaram-se principalmente entre $-1,5 \mathrm{e}+1,5^{\circ} \mathrm{C}$, fornecendo, portanto, variações de 14,0 a 17,0 equivalentes da porcentagem em peso de $\mathrm{NaCl}$. A temperatura de homogeneização total (Thtotal) apresentou-se de modo geral bastante elevada $\left(=450^{\circ} \mathrm{C}\right)$.

Os dados microtermométricos mostraram que a provável nucleação da esmeralda deu-se, aproximadamente, entre $450^{\circ} \mathrm{C}$ e 2000 bars (condições mínimas) e $600^{\circ} \mathrm{C} \mathrm{e}$ 2750 bars (condições máximas), indicando uma natureza hidrotermal-pneumatolítica tardia, de baixa pressão, para as soluções mineralizantes (SOUZA et al., 1990).

Topázio Imperial de Ouro Preto. Jazidas de topázio imperial ocorrem na região situada a sudoeste da cidade de Ouro Preto, MG (sinclinal Dom Bosco), encontrando-se distribuídas em alinhamentos de direção leste-oeste (D’ELBOUX \& FERREIRA, 1975). Foram estudadas as jazidas de Capão do Lana e Caxambu.

Existem muitas controvérsias sobre a gênese dos topázios de Ouro Preto, mas muitos autores, entre eles OLSEN (1971) e FERREIRA (1983), sugerem que os depósitos estão relacionados ao tectonismo e à fase pneumatolítica ligada à atividade magmática geradora do vulcanismo que afetou a região.

Os topázios dessas duas jazidas ocorrem sob a forma de cristais prismáticos terminados, de dimensões entre 1 e $4 \mathrm{~cm}$, apresentando coloração amarelo alaranjada. Possuem freqüentemente um grande número de inclusões fluidas, a maioria sob a forma de canalículos orientados segundo seu eixo c, embora, em alguns casos, apresentem formatos irregulares. São constituídas principalmente por $\mathrm{H}_{2} \mathrm{O}$ e $\mathrm{CO}_{2}$, não possuindo fases sólidas (GANDINI et al., 
1990).

Os estudos microtermométricos dessas inclusões forneceram os seguintes resultados (GANDINI et al., 1990):

a) Caxambu: $\mathrm{TfCO}_{2}$ de $-56,8$ a $-56,6^{\circ} \mathrm{C}$, indicando a presença de $\mathrm{CO}_{2}$ praticamente puro, com variações locais; $\mathrm{ThCO}_{2}$ entre 20,6 e $21,0^{\circ} \mathrm{C}$; Tfclatratos entre 5 e $7^{\circ} \mathrm{C}$, fornecendo salinidades entre 6,0 e 9,0 equivalentes da porcentagem em peso de $\mathrm{NaCl}$; a temperatura de homogeneização total (Thtotal) variou de 270 a $290^{\circ} \mathrm{C}$, sendo que algumas amostras apresentaram valores maiores.

b) Capão do Lana: $\mathrm{TfCO}_{2}$ de $-57,0$ a $-56,8^{\circ} \mathrm{C}$, também indicando presença de $\mathrm{CO}_{2}$ bastante puro, embora com variações locais; $\mathrm{ThCO}_{2}$ entre 11,2 e $12,6^{\circ} \mathrm{C}$; Tfclatratos de 6 a $8^{\circ} \mathrm{C}$, indicando salinidades entre 4,0 e 7,5 equivalentes da porcentagem em peso de $\mathrm{NaCl}$; Thtotal de 270 a $300^{\circ} \mathrm{C}$.

Com esses dados foram calculadas as densidades totais das inclusões para as duas jazidas $\left(0,97\right.$ a $0,99 \mathrm{~g} / \mathrm{cm}^{3}$ - Caxambu e 0,95 a $0,97 \mathrm{~g} / \mathrm{cm}^{3}$ - Capão do Lana), tendo sido construídas as respectivas isócoras. Os estudos microtermométricos mostraram que as condições de aprisionamento das inclusões ocorreram a temperaturas mínimas de $300^{\circ} \mathrm{C}$ e pressões totais superiores a 2500 bars.

As inclusões das demais gemas encontram-se ainda em fase de caracterização. Assim sendo, na ametista de Caçapava (RS) foram observadas grandes quantidades de inclusões bifásicas a temperatura ambiente; na turmalina de São José da Safira (MG) também ocorrem muitas inclusões bifásicas a temperatura ambiente; na andalusita de Santa Tereza (ES) as inclusões são extremamente irregulares, sugerindo a atuação de processos metamórficos complexos. As inclusões das outras ocorrências citadas encontram-se em fase de amostragem e caracterização geológica.

\section{REFERÊNCIAS BIBLIOGRÁFICAS}

D’ELBOUX, C.V. \& FERREIRA, C.M. (1975) Topázio na região de Ouro Preto. Bol.Esc. Minas, Ouro Preto. Publ. Espec. no 1, p.73-79.

EPSTEIN, D.S. (1989) The Capoeirana emerald deposit near Nova Era, Minas Gerais, Brazil. Gems \& Gemology, 25(3):150-158. 
FERREIRA, C.M. (1983) Vulcanismo ácido no Quadrilátero Ferrífero e sua relação com algumas ocorrências e/ou depósitos minerais. In: SIMPÓSIO DE GEOLOGIA DE MINAS GERAIS, 2., Belo Horizonte, 1983. Anais. Belo Horizonte, SBG. p.128-133 (Boletim, 3).

GANDINI, A.L.; SVISERO, D.P.; BELLO, R.M.S.; CARVALHO, F.M.S.; VALARELLI, J.V. (1990) Inclusões fluidas de topázios imperiais das jazidas do Capão do Lana e Caxambu, Ouro Preto, MG. In: CONGRESSO BRASILEIRO DE GEOLOGIA, 36., Natal, 1990. Boletim de resumos. Natal, SBG. p.227-228.

OLSEN, D.R. (1971) Origin of topaz deposits near Ouro Preto, Minas Gerais, Brazil. Economic Geology, 66(4):627-631.

SOUZA, J.L.; MENDES, J.C.; BELLO, R.M.S.; SVISERO, D.P.; VALARELLI, J.V. (1990) Estudos petrográficos, minerabogicos e microtermométricos da esmeralda do Garimpo de Capoeirana, Nova Era, Minas Gerais. In: CONGRESSO BRASILEIRO DE GEOLOGIA, 36., Natal, 1990. Anais. Natal, SBG. V.3, p.1389-1402.

SOUZA, J.L.; MENDES. J.C.; CARIBALDI, E.; SVISERO, D.P. (1989) Aspectos geológicos da área do Garimpo de Capoeirana, Nova Era: uma nova ocorrência de esmeralda em Minas Gerais. In: SIMPÓSIO DE GEOLOGIA NÚCLEO MINAS GERAIS, 5.; SIMPÓSIO DE GEOLOGIA NÚCLEO BRASíLIA, 1., Belo Horizonte, 1989. Anais. Belo Horizonte, SBG. p.94-98 (Boletim10). 